\title{
LEITURAS EDIFICANTES PARA RELIGIOSAS NA DÉCADA DE 1990
}

\author{
Uplifting readings for religious women decade 1990s
}

\author{
GUARIZA, Nadia Maria ${ }^{1}$ \\ UNICENTRO -Paraná / Brasil \\ CARDOSO, Samuel ${ }^{2}$ \\ UNICENTRO -Paraná / Brasil
}

\begin{abstract}
RESUMO: A proposta deste artigo é discutir como as leituras religiosas, especificamente as biografias, agiram como estratégia de recrutamento de religiosas para a Igreja Católica, bem como, uma forma pedagógica para a formação das noviças e de religiosas nos conventos. $\mathrm{O}$ livro analisado é "O mistério das Clausuras" de Afonso de Santa Cruz (1995). Nesta obra o autor seleciona cartas que havia solicitado às religiosas de todo o Brasil, pedindo que ressaltassem o motivo de sua entrada na vida religiosa. Compreendemos as cartas das religiosas como a escrita de si, ou seja, ao escrever sobre si as religiosas pretendiam divulgar uma imagem de si próprias e da vida religiosa. Além disso, analisamos os relatos a partir da perspectiva de gênero, isto é, compreendemos que a representação em torno da vida religiosa feminina está ancorada nos papéis que estas mulheres podem assumir na instituição, em contraposição aos papéis que os homens assumem. Para tanto, empregamos como referencial teórico os seguintes autores: Bourdieu, Scott, Certeau, Durkheim, Eliade.
\end{abstract}

Palavras-chave: Catolicismo ; Gênero ; Biografias.

ABSTRACT: The purpose of this article is to discuss how the religious readings, specifically the biographies, functioned as a recruitment strategy of religious women to the Catholic Church and also as a pedagogical way of upbringing novices and nuns in convents. The book that has been analyzed is "The mystery of the cloisters" (O mistério das Clausuras) by Alfonso de Santa Cruz (1995), in which the author selects letters he had requested to the nuns from all over Brazil, asking them to highlight the reason for their entry into religious life. We understand the letters of these religious women as the writing of themselves, that is to say, when writing about themselves the nuns intended to spread an image of themselves as well as of the religious life. In addition, we analyze the stories from a gender perspective, that is, we understand that the representation about female religious life is anchored in the roles that these women can assume in the institution, as opposed to the roles that men assume. Therefore, we use as theoretical reference the following authors: Bourdieu, Scott, Certeau, Durkheim, Eliade.

Keywords: Catholicism ; Gender ; Biographies.

1 Possui graduação em História pela Universidade Federal do Paraná(1994), especialização em linguagens, imagens e ensino de História pela Universidade Federal do Paraná(1999), mestrado em História pela Universidade Federal do Paraná(2003) e doutorado em História pela Universidade Federal do Paraná(2009). Atualmente é Revisor de periódico da História. Questões e Debates e Adjunto 1 da Universidade Estadual do Centro-Oeste. E-mail: nadiamguariza@gmail.com

2 Mestrando em História área de concentração História e Regiões pela Universidade Estadual do Centro-Oeste.E-mail: samucardoso@live.com

REVISTA RELEGENS THRÉSKEIA - 2018 - UFPR - UEPA 


\section{Introdução}

Durante o século XX a vida religiosa feminina modificou se de maneira significativa, podendo encontrar religiosas reclusas nos conventos e outras de vida ativa que desenvolviam atividades em contato com a comunidade, como o atendimento em hospitais e em escolas.

No quadro do ultramontanismo ${ }^{3}$ estas religiosas de vida ativa desempenharam um papel importante na defesa e na propagação dos preceitos católicos, contudo deveriam realizar estas atividades sob a supervisão de um clérigo e a sua mobilidade espacial era limitada dentro das fronteiras de suas atividades ${ }^{4}$.

As irmãs de vida ativa deveriam se preocupar ainda mais em relação ao seu comportamento, justamente por circularem mais entre as pessoas da comunidade e uma das formas de manterem esta distinção comportamental era o uso do hábito. $\mathrm{O}$ hábito criava um cerco invisível de respeitabilidade, escondendo as formas femininas de seus corpos e dotando-as de um significado sagrado ${ }^{5}$.

Após o Concílio Vaticano II (1963-1965) a vida das religiosas transformou de maneira considerável, a partir de uma concepção de igreja voltada aos pobres as religiosas deveriam cada vez mais atuar em novas frentes para além do hospitalar e educacional. No caso brasileiro a criação das pastorais ${ }^{6}$ permitiu a participação das irmãs em assentamentos de terra, em presídios e outros lugares até então considerados impensáveis a presença feminina. O uso do hábito foi abandonado justamente para minimizar a hierarquização entre as religiosas e os leigos. A aceitação e a adaptação das religiosas a estas mudanças foram variáveis, algumas resistiram, enquanto outras

\footnotetext{
${ }^{3} \mathrm{O}$ termo ultramontanismo foi adotado para denominar uma política do Vaticano a partir da metade do século XIX, os principais traços desta política era uma ofensiva a modernidade, ao socialismo, ao liberalismo e ao protestantismo, enfim todas as ideias que pudessem atingir os parâmetros católicos. Ver Riolando Azzi O Estado leigo e o Projeto Ultramontano. São Paulo: Paulus, 1994. (História do Pensamento Católico - IV)

${ }^{4}$ As religiosas em outros períodos históricos também se dedicaram ao cuidado com os doentes e aos pobres como na baixa Idade Média. Ver Bronislaw Geremek. Os filhos de Caim: vagabundos e miseráveis na literatura europeia: 1400-1700. São Paulo: Companhia das Letras, 1995.

${ }^{5} \mathrm{O}$ uso do hábito é uma norma antiga na vida conventual remontando ao período medieval e confirmada pelo Concílio de Trento (1545-1563).

${ }^{6}$ Segundo Gabriele dos Anjos as noções de comunidade eclesiásticas de Base e as Pastorais estariam articuladas a uma tendência mais "progressista" da Igreja, porque a proposta desta tendência seria a primazia da comunidade de crentes e que esta comunidade se engajaria em trabalhos associados às pastorais sociais. ANJOS, Gabriele dos. Liderança de mulheres em pastorais e comunidades católicas e suas retribuições. Campinas, Cadernos Pagu, n. 31, jul-dez, 2008, pp. 509.534. p. 511.
}

REVISTA RELEGENS THRÉSKEIA - 2018 - UFPR - UEPA 
adotaram as novas diretrizes do Vaticano II $^{7}$.

Contudo, a forma de viver das enclausuradas continuou a ser considerada a vida religiosa por excelência, pois estavam totalmente afastadas das preocupações mundanas. O livro "O mistério das Clausuras" de Afonso de Santa Cruz ${ }^{8}$ (1995) mostra os relatos de mulheres que optaram por ela, porém ingressaram na vida religiosa pela inspiração de religiosas ativas, sendo assim, as irmãs de vida ativa realizaram a sua missão de recrutar pessoas para a causa católica.

O livro analisado neste artigo corresponde justamente a este período de mudanças, resistência e adaptação das religiosas, em que muitos livros publicados contavam histórias de religiosas e de santas. Este tipo de literatura edificante tem uma tradição secular na Igreja Católica, mas o que pretendemos é compreender as especificidades destes escritos neste contexto específico.

Quais as qualidades ressaltadas para que as mulheres desenvolvam para tornarem-se religiosas nas décadas de 1960 a 1980? Desejamos estudar a historicidade das leituras edificantes produzidas por Afonso de Santa Cruz, mais especificamente na seguinte obra: "O Mistério das Clausuras”. E mais especificamente compreender como estas leituras serviram como meio de recrutamento e de formação pedagógica para a vida religiosa.

\section{As leituras edificantes}

As leituras edificantes analisadas aqui transitam entre o estilo biográfico e o hagiográfico. O estilo hagiográfico é o mais tradicional no catolicismo, isso não significa que não tenha sofrido transformações ao longo de sua história, e assim não podemos compreender este estilo de forma a-histórica. A história de santos e de santas se modificam a partir dos interesses do contexto, seja da congregação que abriga a história do santo (CERTEAU, 2006) quanto da própria autoria que não escapa das

\footnotetext{
${ }^{7}$ Alguns estudos apontam que as religiosas que estavam acostumadas a usar o hábito não acataram as orientações do Concílio Vaticano II, continuando a usá-lo. Ver Susana Biachi em Acerca de las formas de la vida religiosa feminina. Uma aproximación a la historia de las congregaciones em la Argentina. Pasado Abierto, Mar Del Prata/AR, v. 1, n. 1, 2015.

${ }^{8}$ Afonso de Santa Cruz é um sacerdote jesuíta que escreveu mais de 115 livros sobre santos e beatos católicos. Nascido em Santa Cruz no Rio Grande do Sul, Afonso Gessinger tornou se vigário em 1956, estudou na Alemanha e na Itália e trabalhou durante 40 anos em Curitiba no Colégio Medianeira e foi reitor da Igreja do Rosário. Disponível em: https://pt.aleteia.org/2015/05/08/afonso-de-santa-cruz-commais-de-115-livros-sobre-vidas-de-santos-ele-e-um-brasileiro-que-voce-precisa-conhecer/ Acesso em: 10 jul 2018.
} 
ideias de sua época (BOURDIEU, 2006).

No período moderno muitas hagiografias assumiram contornos de biografias, os seus autores passaram a se preocupar com os efeitos de realidade que se apresentam nas biografias. Contudo, deve-se ter em mente que a hagiografia trata da vida de uma pessoa que é considerada sobrenatural ou que está acima dos demais seres humanos, são seres excepcionais, enquanto as biografias não possuem este toque ou preocupação, não obstante algumas biografias de pessoas públicas pretendem mostrá-las como seres excepcionais e geniais (GUARIZA, 2015).

De qualquer forma, o que nos interessa aqui é analisar o modelo de vida religiosa para as mulheres, portanto, este artigo desenvolve uma abordagem a partir da categoria gênero (SCOTT, 1990). No catolicismo por tradição e por dogmática as mulheres ocupam um lugar secundário na instituição. O papel central é do sacerdote, ou seja, um homem que é autorizado a receber a ordenação, enquanto que as freiras podem ser religiosas, contudo elas nunca serão ordenadas, isto é, na economia simbólica da instituição elas nunca ocuparam o cargo máximo (BOURDIEU, 2007).

O sacerdote tem o privilégio e monopólio sagrado de transformar a hóstia em corpo de Cristo no ritual do sacrifício na missa, o ponto alto simbolicamente falando do catolicismo. Desta forma, enquanto as mulheres não puderem ser ordenadas como sacerdotes haverá esta diferenciação simbólica entre homens e mulheres na instituição. Assim como outras que são estabelecidas a partir desta diferenciação por gênero.

Para Scott (1990) os papéis de gênero são construídos socialmente e estes papéis criam hierarquias entre homens e mulheres, no caso estudado neste artigo trata se de uma instituição religiosa que atribui papéis específicos para mulheres e para homens, e estes papéis criam uma situação de desigualdade de poder entre os gêneros.

Compreendemos que este livro tinha por objetivo estimular novas vocações à vida religiosa feminina e, ao mesmo tempo, divulgava representações (CHARTIER, 1991) em torno da figura da freira. Segundo Chartier (1991) o autor ao representar cria a própria matriz da vida real, ou seja, ao escrever e escolher quais narrativas representam adequadamente a vida religiosa feminina, os autores e os editores criam expectativa do que seria a vida religiosa feminina.

Sendo assim, as cartas escritas expressam um ideal de vida religiosa e a seleção que Afonso de Santa Cruz faz entre as cartas enviadas também passa por critérios do 
que seria a vida conventual. Podemos compreender como Bourdieu (2006) expõe que a biografia é uma obra pedagógica, ou seja, neste caso as cartas serviriam para a formação religiosa das noviças e de outras religiosas já consagradas com a finalidade de criar normas de comportamento para elas.

Iniciamos a análise pelo testemunho da Irmã Carmelita do Carmelo Santa Teresa Cabeçudas de Itajaí (SC) que para decidir sobre o destino de sua vida pediu um sinal divino.

Um dia pensei: Vou fazer mais uma novena, se o sinal vier...! Disse: "Ó Teresinha, vou começar outra novena, que me dês pela mão de uma criança uma rosa em botão, de tal qualidade, depois não te pedirei mais nada..."

Marquei uma qualidade de rosas, que naquele lugar onde eu estava então, nunca tinha visto. E pensei: "Se a rosa vier, não esperarei mais. A vontade de Deus estará manifesta".

No meio da novena, num domingo, por acaso atrasei para a missa das crianças. Quando sozinha cheguei na praça da igreja, ouvi o barulho de um coro que vinha e parou na frente da igreja.

Eu pensei: "Gente atrasada como eu". Mas não olhei para ver. Continuei andando, nisto senti os passos de uma criança, correndo atrás de mim. Logo disse: "Irmã!" Eu olhei para trás. Era uma linda menina, vestida de branco. O vestido todo franzido. A menina olhando-me disse: "Irmã, esta rosa é para a senhora.

Era a rosa que eu pedia, bem igual. Peguei a rosa, agradeci à menina, abracei-a e ela voltou para o coro, que seguiu viagem.

Pensei de como Deus preparou tudo... Entrei na Igreja, fiquei no último banco. Não tinha forças para andar mais. Eu tremia... suava, não sei o que se passava. Disse: "Jesus, agora não quero mais sinais. Vou ao Carmelo. Sei que esta é a vontade do Pai”. (CRUZ, 1995, p.22-23).

É recorrente na tradição hagiográfica o pedido de sinais divinos no momento decisivo dos santos, o sinal de Deus por forma de milagre é um indício da graça e do caminho a percorrer. A irmã Carmelita do relato se inspira na tradição hagiográfica para pedir este sinal, além disso, a escolha pela rosa que simbolicamente é representada em várias hagiografias como a de Santa Rita de Cássia e na iconografia do Sagrado Coração de Maria.

Ela narra que tinha muito a necessidade de receber de forma materializada 
respostas seja por intermédio da fé ou pela busca do sobrenatural. Para conseguir o sinal divino para decidir o que fazer, muitas vezes as religiosas pedem em oração. Os sinais divinos são indícios de que Deus a escolheu para a vida religiosa.

Como pode ser perceptível é a presença da crença e do rito nas narrativas das hagiografias. Segundo Durkheim (1996) deve-se compreender a religião a partir de suas partes, podemos então entender as manifestações religiosas através de seus principais grupos: a crença e o rito, sendo considerado como crença tudo o que se caracteriza como convicção e interpretação, e rito como formas organizadas com um padrão e execuções com finalidades. Sendo diferenciado então como subjetivo e o praticável (DURKHEIM, 1996, p.19).

Podemos perceber de forma enfática a presença da crença e do rito no testemunho da Ir. M. José do Verbo Encarnado, do Mosteiro Nazaré- Clarissas pobres da cidade de Lages- SC, quando por meio da crença se opera a mudança no mundo por intermédio da entrega total em oração e devoção a um Ser Superior, e o rito a partir de atitudes regradas da religiosa ao falar da vestição e do noviciado. Assim ela descreve:

Eu nasci numa família católica praticante, e minha irmã mais velha era religiosa de vida ativa. Dois irmãos meus fizeram uma experiência. E eu, feliz, da vida, fiquei pensando na idéia. (...)

Nós somos orantes e devemos rezar pelo mundo inteiro; é o nosso emprego. Assim como existem religiosas de vida ativa, nós, nossa vocação é dar ao mundo também uma ajuda, mas com oração: só, diante de Deus, pedindo pela santificação do mundo. E é claro que junto pedimos a nossa própria santificação. (...)

Um ano após o ingresso fiz a vestição. Era início da década de setenta. Estava tão feliz aquele dia, que pensava: um homem não saberia fazer-me feliz assim ${ }^{9}$, porque esta felicidade brota das profundezas do coração, lá onde só Deus mora, no íntimo de cada ser humano. (CRUZ, 1995, p. 7576-77).

Como podemos perceber no relato de Ir. Maria José há uma importância nas duas ramificações da vida religiosa seja na contemplativa ou na vida ativa, cada uma traz uma característica importante. As de vida contemplativa rezam no silêncio e calmaria de seus mosteiros, buscam a santificação da humanidade sendo esta a colaboração destas irmãs. Por outro lado, as de vida ativa estão mais próximas das ações mundanas e, também, colaboram para que os mais necessitados possam receber a santificação por meio de suas ajudas.

\footnotetext{
${ }^{9}$ Grifos Nossos.
} 
É perceptível também que muitos filhos de famílias do interior eram direcionados a completar a sua educação em seminários e internatos de irmãs, o que poderia levá-los à vida religiosa. No caso Ir. M. José do Verbo Encarnado foram dois irmãos e uma irmã, por isso eles serviram de inspiração e de modelo para ela, optando pela vida religiosa mais radical da clausura. E ela ressalta que nenhum homem a faria feliz como a vida religiosa, mostrando que o casamento não é uma aptidão inata da mulher, Leila Mezan Algranti (1993) ao estudar conventos e recolhimentos no período colonial brasileiro observa que muitas mulheres escolhiam a vida religiosa no lugar do casamento, porque este as faria se submeter à autoridade do marido e o perigo das sucessivas gravidezes.

Ao adentrar a vida religiosa por meio da consagração, as freiras passam por um rito de passagem, em que abdicam dos sinais particulares e familiares é exigido para ingressar em uma nova comunidade. Segundo Durkheim (1996, p. 19) o rito se exprime por meio da crença, sendo que a compreensão das crenças em seu aspecto mais incognoscível é possível pelo emprego de dois conceitos antagônicos: o profano e o sagrado.

No caso do ritual de passagem das noviças para a vida consagrada é a transposição da esfera profana para a sagrada, na qual é requerido a purificação. Sendo esta transmutação um rito, que indicara o nascer na vida religiosa (DURKHEIM, 1996, p. 22).

Podemos perceber a iniciação na vida sagrada abandonando a vida profana no depoimento da Ir. Rita Maria de Deus Trinto, do Mosteiro de "Nazaré" em Lages-SC

Até os 18 anos minha participação na vida da Igreja resumia-se ir a missa aos domingos. Deus para mim, era "algo" muito distante, lá no céu, que pouco influenciava em minhas atitudes e em minha vida.

Eu estudava, fazia um ou outro curso profissionalizante, preparando-me para trabalhar fora, pois precisava ajudar em casa. Além disso, tinha os amigos, namorava, gostava de festas. Dançar era a minha alegria. Também gostava muito de passear, viajar, ir à praia ou piscina, ao cinema e shows.

Mas uma semente, que produzia sede do absoluto, já estava plantada em meu coração e, às vezes, sentia um desejo profundo de ser peregrina: sair por aí, sem ter segurança humana nenhuma, nem estar ligada afetivamente só a um pequeno grupo de pessoas, sem entrar neste ritmo de trabalho remunerado, mas simplesmente ir caminhando, parando aqui e ali, conhecendo pessoas e realidades novas e diferentes, ajudando no que pudesse, livre como os pássaros.

Neste tempo estava na moda fazer um tal teste vocacional, para perceber suas aptidões e assim fazer uma escolha consciente da Profissão. Lembro- 
me que fugia de tal teste, pois pensava: se eu começar a dizer que gostaria de trabalhar sem remuneração, que adoraria ajudar os necessitados, que desejava ser livre como os pássaros... iriam me responder, que provavelmente eu deveria procurar um convento.

E ser freira era a última coisa que eu queria para mim. Isso nem me passava pela cabeça. Não, não podia imaginar. Com a vida que eu levava, naturalmente ia me preparando para o matrimônio.

Mas chegou um tempo em que travou-se uma forte luta interior. Tudo o que eu fazia não me saciava. (...)

Neste encontro de jovens, no último dia, houve colocações sobre o Matrimônio, o Sacerdócio, e a Vida Religiosa. As palavras do conferencista, ao falar sobre a vocação religiosa, eram ao mesmo tempo, água que saciava minha sede e fogo que queimava o meu coração.

Parecia-me que tudo o que desejava poderia ser vivido neste modo de vida consagrada.

(CRUZ, 1995, p.79-80-81-82).

Na narrativa da Irmã Rita aparece como alternativa para as mulheres de seu período a vida de casada e a vida religiosa, e por seu comportamento juvenil tudo indicava que escolheria a vida do matrimônio, ela relata que a vida de diversão com o tempo pareceu sem sentido, enquanto que no encontro para os jovens se sentiu tocada pela vida religiosa.

Rita queria se sentir como um pássaro livre, novamente é notável que as irmãs comparem a vida religiosa à liberdade, enquanto que a vida convencional do casamento e do trabalho era considerada limitante. Geralmente pensa-se que a opção pela vida religiosa é marcada apenas pela renúncia, talvez por causa dos votos que elas devem professar, em todo caso para muitas a vida religiosa era mais libertadora do que a vida de casada.

\footnotetext{
Conheci muitas Congregações e ordens Contemplativas, as quais me atraíram e a luta para decidir foi grande. O senhor me apontou o silêncio e a pobreza de um Mosteiro de Clarissas. Ir visitar o Mosteiro era como fazer uma visita ao paraíso. Subia aquela colina com tanta alegria, tanta disposição. (...)

Aqui, no silêncio de um claustro, escondida com Cristo em Deus, sou Peregrina, sinto-me membro vivo e atuante desta Igreja. Vivo suas dores e suas alegrias; sofro com os desafios e espero novos céus e nova terra. (CRUZ, 1995, p.82-83).
}

Compreende-se que essa dissemelhança entre o sagrado e profano é tamanha que se volta para uma certa rivalidade, entendendo-o como dois espaços distintos, no qual se 
estiver ligado a um não pode estar preso a outro. Portanto, é encorajado o indivíduo a deixar inteiramente o mundo profano para assim seguir na totalidade o mundo do sagrado ou a vivência religiosa. Assim tem se a necessidade do enclausuramento, como instinto de privar-se do mundo profano. "Daí o ascetismo místico, cujo objetivo é extirpar do homem tudo o que nele pode permanecer de apego ao mundo profano" (DURKHEIM, 1996, p.23).

De acordo com Eliade:

\begin{abstract}
$\mathrm{O}$ sagrado equivale ao poder e, em última análise, à realidade por excelência. O sagrado está saturado de ser. Potência sagrada quer dizer ao mesmo tempo realidade, perenidade e eficácia. A oposição sagrado/profano traduz se muitas vezes como uma oposição entre real e irreal ou pseudo real. (Não se deve esperar encontrar nas línguas arcaicas essa terminologia dos filósofos - real-irreal etc. -, mas encontra-se a coisa.) É, portanto, fácil de compreender que o homem religioso deseje profundamente ser, participar da realidade, saturar-se de poder. (ELIADE, 1992, p. 16)
\end{abstract}

Poderíamos pensar que as mulheres que optaram pela vida religiosa também desejavam participar da superioridade concedida pela esfera religiosa. Demonstra Durkheim (1996), que a crença surge com a intenção de repassar o que é de natureza sagrada e suas ligações com tudo que a cerca, e até mesmo com seu oposto o profano, "os ritos são regras de conduta que prescrevem como o homem deve comportar-se com as coisas sagradas" (DURKHEIM, 1996, p.24).

A religião desperta no homem uma visão ainda não percebida por aqueles que nela não estão integrados, isto se demonstra na convivência cotidiana das pequenas coisas, ajudando tais convivências a entender o sentido da vida e como devemos agir diante das dificuldades, o homem percebe-se ou "acredita-se salvo do mal, seja qual for a forma, aliás, que conceba o mal. O primeiro artigo de toda a fé é a crença na salvação pela fé" (DURKHEIM, 1996, p.459). PONTUAÇÃO

Assim como podemos ver este sofrimento em prol da salvação que teve que enfrentar seus familiares em nome de um bem maior que desejava, descrito no testemunho da Carmelita que de acordo com o autor Afonso de Santa Cruz "por motivo de prudência, omitimos o nome da carmelita, e do Carmelo e cidade":

Percebia a diferença: o vazio da igreja protestante e a plenitude da Igreja Católica. Sentia e via, então, como que o "verdadeiro Jesus" é a Verdade. 


\begin{abstract}
Meu pai percebeu meu procedimento, começou a me castigar severamente, humilhando-me diante dos irmãos e dos crentes, privandome dos passeios da família, etc...

Aos 12 anos, clandestinamente, procurei um sacerdote e uma família católica, pedindo que me ajudassem, pois queria ser batizada. O sacerdote que ouviu minhas confidências, examinou-me e achando-me bem preparada, batizou-me e deu a $1^{\mathrm{a}}$ comunhão.

Senti tanta felicidade, que chegando em casa, quase não consegui esconder minha celeste alegria, por ter recebido jesus e ser católica. Só depois de um ano minha família soube do ocorrido. Meu pai ficou tão indignado, que mudou para outra cidade, podendo, assim, esconder sua "vergonha". Nessa cidade nunca deixei de ir à missa. (CRUZ, 1995, p.44-45-46)
\end{abstract}

O relato da irmã que na infância fora educada a partir das ideias religiosas de seu pai que era pastor na Assembleia de Deus, tomou contato com o catolicismo na escola e logo se sentiu atraída, o pai ao descobrir considera a atitude da filha como uma desobediência a sua autoridade paterna e a expulsa de casa. É interessante que a vocação da irmã ocorre a partir do trânsito religioso dela da Assembleia de Deus ao catolicismo, o que provocou a ruptura familiar, sendo acolhida pelo bispo de outra cidade. As carmelitas se tornaram a sua nova família, substituindo a família de origem.

É visível que todo o ser que tenha participado de uma instituição religiosa presenciou ou foi protagonista de atos que promove sensações emocionais positivas, para os membros desta religião comprova sua proximidade com o sobrenatural divino, há de se entender que para estes fiéis isto faz parte se sua crença. "As crenças religiosas se baseiam numa experiência específica cujo valor demonstrativo, num certo sentido, não é inferior ao das experiências cientificas, embora diferentes" (DURKHEIM, 1996, p.460).

Na descrição do testemunho da Irmã Maria Margarida do Mosteiro da Visitação em Barbacena- MG, novamente é possível perceber o papel fundamental dos educandários no desenvolvimento de vocações, sua mãe era espírita, contudo a colocou para estudar em um colégio católico, mais tarde o seu pai a enviou para um educandário. Portanto, os pais poderiam não ser católicos, mas reconheciam as escolas católicas como um excelente lugar de formação educacional para as meninas e moças. Irmã Maria Margarida também vivencia a ruptura familiar com a separação dos seus pais.

Ivan Manoel (1996) enfatiza a importância da educação religiosa para as famílias de classe média e alta, no caso feminino, educava se moralmente as moças para 
que elas fossem esposas fieis e obedientes. Obviamente que uma das estratégias da Igreja Católica era educar as futuras mães para que educassem catolicamente os seus filhos, além disso, os educandários eram verdadeiros "celeiros" para o estímulo à vida religiosa.

Como podemos perceber no testemunho de Irmã Maria Margarida do Mosteiro da Visitação em Barbacena- MG, acima descrito, houve uma aproximação inicial através da entrada no educandário aos 13 anos. Esta iniciação na vida religiosa foi por meio do convívio com as irmãs Oblatas do Santíssimo Redentor que pela forma como agiam na convivência e no tratamento com o próximo foram cativando Ir. Maria Margarida, como ela mesma descreve "fui tratada com afeto maternal, ensinando-me a amar o bom Deus, mais com o exemplo de suas vidas do que com as palavras. Vivia alegre e descontraída e fui tornando-me cada dia mais piedosa” (CRUZ, 1995, p.34).

O seu relato também demonstra a importância dos retiros para os jovens no recrutamento de religiosos e de religiosas, assim as publicações católicas como ela menciona em seu relato.

O educandário era dirigido por religiosas de vida exemplar (Irmãs Oblatas do Santíssimo Redentor). Elas me acolheram como "A graça de Deus" (...)

No mês de setembro daquele mesmo ano (1958), fiz o meu $1^{\circ}$ retiro de 5 dias, pregado por um sacerdote redentorista. Eu o vivi intensamente. Durante o dia o sino tocava chamando as educandas ora para ouvir o pregador, ora para a meditação pessoal.

Eu estava encantada e no meu fervor de adoradora disse para o senhor: "Jesus, eu queria uma vida assim, que toda hora deixasse o trabalho e fosse rezar". Imediatamente fez-se um grande silêncio em todo o meu ser e eu ouvi que me diziam: "Por que não vai ser freira?"

Aquelas palavras colheram-me de surpresa, respondi logo: "Eu, freira?" (...) Passaram-se várias semanas... Um dia estava folhando despreocupadamente um livro de oração e de repente, no rodapé de uma página, deparei com umas letrinhas, que me chamaram a atenção.

Dizia que os estatutos originais do Apostolado de oração estava guardados na cela, onde morreu Santa Margarida Maria Alacoque, religiosa da Ordem da Visitação de Santa Maria, em Paray le Monial, França. Ao ler essas palavras senti um choque, meu coração começou a bater fortemente, como se tivesse encontrado algo há muito tempo procurado. (...)

Para lá eu não vou... deve ser ilusão, conclui. Mas já não me foi possível esquecer aquele nome, aquela emoção.

Pouco depois soube que havia um Mosteiro da Visitação em Niterói-RJ (que mais tarde foi transferido para Barbacena-MG), então, não tive mais dúvidas, era lá que o senhor me queria. (CRUZ, 1995, p. 34-35-36)

No trecho de sua carta que ela descreve que avida consagrada é a única coisa que 
preenche todo o desejo de viver, irmã Margarida comenta que há 29 anos pertencia a vida consagrada no mosteiro da Visitação e que encontrou neste lugar tudo o que procurava como a vida de oração, trabalho, caridade e alegria e acrescenta:

\begin{abstract}
A visitandina deve como Maria ter uma alma sensível às inspirações do alto e, deixando suas próprias comodidades, seus interesses pessoais, partir apressada para servir. Deve ser alma de colóquios espirituais, comunicando o Espírito Santo àqueles que se aproximarem dela.

Por fim, a exemplo de nossa Mãe Santíssima deve ser uma alma jubilosa, sempre exultando em Deus seu Salvador e transmitindo alegria aos que com ela convivem. É belo este mistério!

Peço ao bom Deus e a Nossa Senhora que revelem a muitas jovens generosas este caminho de santidade e que muitas façam sua opção pela nossa santa Ordem da Visitação, podendo assim constatar a veracidade do meu testemunho: "Deus é bom e feliz o coração que O ama!" (CRUZ, 1995, p. 36-37)
\end{abstract}

Pela narrativa da Ir Maria Madalena é possível perceber a importância das leituras religiosas, porque o desejo profundo de ser religiosa com a participação do retiro que aumentou e que se confirmou com a leitura de um livro de orações. Ao mesmo tempo, a irmã Margarida manifesta o desejo de que a sua história motive jovens a ingressarem na vida religiosa do Mosteiro.

A leitura que Ir. Maria fez proporcionou um caminho a seguir. para Certeau:

\begin{abstract}
O fosso entre as "Biografias" eruditas e as "Vidas" edificantes se amplia. As primeiras são críticas, menos numerosas, e tratam de santos mais antigos, quer dizer, são ao mesmo tempo relativas a uma pureza primitiva do verdadeiro e a um privilégio elitista do saber. As segundas, como milhares de "Flores dos santos" populares, são muito difundidas e consagradas a contemporâneos mortos "em odor de santidade". (CERTEAU, 2006, p.268).
\end{abstract}

Ir. Maria foi conquistada por meio da leitura no rodapé de uma página, que espalhou o desejo ou como descreve Certeau (2006) "Flores dos santos" que a cativou, bem como também o convívio com as irmãs Oblatas do Santíssimo Redentor que espalharam o amor maternal e humanitário. Como descreve Ir. Maria "Elas me acolheram como a graça de Deus". (CRUZ, 1995, p.34).

Também de acordo com Certeau (2006) nos primórdios da vida cristã, foram os hagiográficos diferenciados mundialmente na forma de escrever o texto, isto porque as mais importantes e principais escritas era os livros canônicos que compunham as principais "Escrituras”, de acordo com Certeau (2006) "se diz de Melânia que uma vez 
saciada dos livros canônicos ou das Compilações de homílias, ela percorreu as vidas dos Padres como sobremesa".

Já para os leitores destas hagiografias se torna o momento mais alegre após a leitura. Por ser uma leitura de fácil entendimento que pode ser lida em momentos ociosos do lazer. Com o intuito de buscar alimentar-se do que é espiritual e contemplativo. Se distinguindo da obrigatoriedade do aprendizado como norma pedagógica ou dogmática, traz a renovação e entretenimento. (CERTEAU, 2006, p. 270). Podemos entender que a leitura nas “quais é necessário acreditar ou praticar, ela [a leitura] oscila entre o crível e o incrível, propõe o que é lícito pensar e fazer. Sob estes dois aspectos criam, fora do tempo e da regra, um espaço de "vacância" e de possibilidades novas". (CERTEAU, 2006, p. 270).

\section{Considerações finais}

O livro "O mistério da clausura" de Afonso de Santa Cruz se configura como uma leitura que pretendia estimular as jovens a se sentirem atraídas pela vida religiosa. Os relatos que analisamos neste artigo demonstra que a ideia era mostrar para as jovens da década de 1990 que era possível até uma moça festeira ingressar na vida religiosa. Se a família não colabora para a formação católica das filhas, muitas famílias as enviavam para escolas de freiras.

Nestas escolas elas eram convidadas a participar de retiros e tinham acesso à leituras religiosas, o próprio exemplo das irmãs que muitas vezes substituíam a ausência materna e também o espírito comunitário poderiam substituir as suas famílias desestruturadas. Os relatos também mostram às jovens que a vida conventual não era só privação, mas muitas vezes podem ser espaços de liberdade. Liberdade das atribuições do trabalho, da família, dos filhos e do marido. Elas poderiam dedicar-se às leituras e orações, sem as preocupações mundanas. Os relatos expressam a felicidade de todas ao perceber a sua vocação e depois a vida conventual.

Sendo assim, podemos pensar o livro "O mistério da clausura" como uma obra para estimular a vida religiosa, considerando o declínio da vida religiosa na metade do século XX (NUNES, 1997), a igreja precisava desta estratégia para tentar repor as irmãs idosas e falecidas. As irmãs no decorrer do século XX tiveram papel fundamental para os projetos da Igreja e por isso a importância em recrutar novas religiosas. 


\section{Referências}

ALGRANTI, Leila Mezan. Honradas e devotas: mulheres da colônia. Condição feminina nos conventos e recolhimentos do Sudeste do Brasil, 1750-1822. Rio de Janeiro, José Olympio e Brasília, Edunb, 1993.

BOURDIEU, Pierre. A ilusão biográfica. In: AMADO, Janaína; FERREIRA, Marieta de Moraes. Usos e abusos da história oral. $8^{\text {a }}$ ed., Rio de Janeiro, FGV, 2006.

BOURDIEU, Pierre. A economia das trocas simbólicas. São Paulo: Perspectiva, 2007.

CHARTIER, Roger. A história cultural: Entre práticas e representações. Tradução: GALHARDO, Maria Manuela. 2a ed., Difel, Rio de Janeiro, 2002.

CHARTIER, Roger. O mundo como representação. Revista Estudos Avançados. V. 11, n.5, São Paulo: USP, 1991.

CERTEAU, Michel de. A escrita da história. Tradução: MENEZES, Maria de Lurdes. $2^{\text {a }}$ ed., Rio de Janeiro, Forense Universitária, 2006.

DURKHEIM, Émile. As formas elementares da vida religiosa: o sistema totêmico na Austrália. Tradução: NEVES, Paulo. 1ª ed., São Paulo, Martins Fontes, 1996.

ELIADE, Mircea. O sagrado e o profano: A essência das religiões. Tradução Fernandes, Rogério. $1^{a}$ ed., São Paulo, Martins Fontes, 1992.

GUARIZA, Nadia Maria. A história de religiosas brasileiras: Entre biografias e hagiografias. Diálogos (Maringá online), v.19, n.3, p.1253-1281, Set.- Dez/2015.

MANOEL, Ivan. Igreja e educação feminina (1859-1919): uma face do conservadorismo. São Paulo: UNESP, 1996.

NUNES, Maria José Rosado. Freiras no Brasil. In: PRIORI, Mary (org.). História das mulheres no Brasil. São Paulo: Contexto, 1997.

SCOTT, Joan. Gênero: uma categoria útil de análise. Educação e Realidade. Porto Alegre, v. 16, n.2, p. 5-22. jul-dez, 1990.

Fontes

CRUZ, Afonso de Santa. O mistério das clausuras. Edições Rosário, $1^{\mathrm{a}}$ e $2^{\mathrm{a}}$ ed., Curitiba, 1995. 